\title{
Properties of Amorphous SiC Coatings Deposited on WC-Co Substrates
}

\author{
A.K. Costa, S.S. Camargo Jr* \\ Engenharia Metalúrgica e de Materiais, Universidade Federal do Rio de Janeiro \\ C.P. 68505, 21945-970 Rio de Janeiro - RJ, Brazil
}

Received: January 02, 2002; Revised: September 30, 2002

\begin{abstract}
In this work, silicon carbide films were deposited onto tungsten carbide from a sintered $\mathrm{SiC}$ target on a r.f. magnetron sputtering system. Based on previous results about the influence of r.f. power and argon pressure upon the properties of films deposited on silicon substrates, suitable conditions were chosen to produce high quality films on WC-Co pieces. Deposition parameters were chosen in order to obtain high deposition rates (about $30 \mathrm{~nm} / \mathrm{min}$ at $400 \mathrm{~W} \mathrm{rf}$ power) and acceptable residual stresses $(1.5 \mathrm{GPa})$. Argon pressure affects the energy of particles so that films with higher hardness $(30 \mathrm{GPa})$ were obtained at low pressures $(0.05 \mathrm{~Pa})$. Wear rates of the coated pieces against a chromium steel ball in a diamond suspension medium were found to be about half of the uncoated ones. Hardness and wear resistance measurements were done also in thermally annealed (200-800 ${ }^{\circ} \mathrm{C}$ ) samples revealing the effectiveness of $\mathrm{SiC}$ coatings to protect tool material against severe mechanical degradation resulting of high temperature (above $500{ }^{\circ} \mathrm{C}$ ) oxidation.
\end{abstract}

Keywords: silicon carbide coatings; tungsten carbide tools

\section{Introduction}

Coatings based on hard materials are specially suitable for the purposes of protection against metallurgical tools wear. The association of properties involving high hardness and thermal stability with low wear rates and friction coefficient is the main goal to achieve. Silicon carbide is a material that presents these features but have being quite unexplored mainly due to its sometimes poor adhesion to metallic substrates.

Thin films of silicon carbide and silicon-carbon alloys are of great scientific and technological interest since these materials present an outstanding set of properties like good mechanical resistance ${ }^{1}$, high hardness ${ }^{2}$ and very high thermal stability ${ }^{1,3,4}$. Their applications may range from protective coatings against corrosion of stee ${ }^{5,6}$ to microelectronic devices $^{7}$ and from $\mathrm{X}$ ray mask materials ${ }^{8}$ to protection of thermonuclear reactor walls ${ }^{9}$, among others. These films can be deposited by a variety of techniques such as laser assisted deposition ${ }^{10}$, dynamic ion mixing ${ }^{11}$, plasma enhanced chemical vapor deposition ${ }^{12}$, magnetron sputtering ${ }^{2}$ and many others. From the various possible choices, magnetron sputtering appears to be a very attractive one due to its relative simplicity, high attainable deposition rates and wide acceptance by industry. At the low temperatures $\left(\mathrm{T}<500^{\circ} \mathrm{C}\right)$ generally necessary for most applications $\mathrm{SiC}$ films are amorphous and can be produced with hardness comparable to that of crystalline $\mathrm{SiC}^{3,13,14}$.

The so called hardmetals such as WC-Co are widely used as cutting tools material since their development in the 1920's due to their high hardness, strength and fracture toughness ${ }^{15,16}$. However, machining conditions usually submit the contact area of the tools surface to temperatures in the range of 600 to $1300{ }^{\circ} \mathrm{C}^{15,16,17}$, where the mechanical properties of cemented tungsten carbide are strongly degraded mainly due to severe oxidation ${ }^{16}$. Therefore, $\mathrm{SiC}$ is a promising material to be used as protective coating for WC cutting tools due to its outstanding thermal stability and much higher hardness. SiC thin films also present a minimal thermal expansion coefficient mismatch when compared to WC-Co $\left(5.3 \times 10^{-6}\right.$ vs. $\left.5.4 \times 10^{-6} \mathrm{~K}^{-1}\right){ }^{1}$.

In the present work we carried out an investigation of $\mathrm{SiC}$ films deposited by rf magnetron sputtering with the aim of developing a material for application as metallurgical and protective coatings. In previous works mechanical (hardness and stress) and microtribological properties of the films and their relation to the deposition parameters were determined $^{3,14}$. From those results suitable conditions were chosen to produce films with hardness values at least equivalent to that of crystalline $\mathrm{SiC}(26-28 \mathrm{GPa})^{18}$ at a reasonably 
high deposition rates. This could be achieved at high enough applied rf power and low argon pressures. Additionally, under such conditions the smoothest surfaces with the lowest friction coefficients were obtained ${ }^{14}$.

\section{Experimental}

Silicon carbide films were deposited with a rf magnetron sputtering system (US Gun II) from a 3" sintered, commercial grade $\mathrm{SiC}$ target using pure argon as sputtering gas. Commercial polished WC-Co cutting tools and single crystalline Si (100) were used as substrates and placed on a unheated sample holder at about $7 \mathrm{~cm}$ from the target. Hardmetal substrates were cleaned by alkaline degreasing followed by ultrasonic bath and in situ sputtering. Selected deposition conditions were: $\arg$ on pressure $\mathrm{P}=5.5 \times 10^{-2} \mathrm{~Pa}$, rf power $\mathrm{P}_{\mathrm{RF}}=400 \mathrm{~W}$, substrate bias $\mathrm{V}_{\mathrm{B}}=-30 \mathrm{~V}$ and no intentional substrate heating. Films were produced with thickness of around $5 \mu \mathrm{m}$ on WC-Co substrates and $2.5 \mu \mathrm{m}$ on reference Si substrates. After deposition coated and uncoated hardmetal samples were submitted to thermal annealing in ambient air for $30 \mathrm{~min}$ at temperatures up to $800{ }^{\circ} \mathrm{C}$. Samples deposited on silicon substrates were annealed for the same time in vacuum $\left(\sim 10^{-5} \mathrm{~Pa}\right)$ at temperatures up to $1100{ }^{\circ} \mathrm{C}$.

A precision ball-crater apparatus was used to perform both thickness measurements and abrasive wear resistance tests. It helped also to give a visual evaluation of adhesion of the coatings, since poor adhered coatings produced detached grains that left deep scratches on the spherical craters. Tests were performed with a $30 \mathrm{~mm}$ diameter chromium steel bearing rotating at $50 \mathrm{rpm}$ with a $0.1 \mu \mathrm{m}$ diamond aqueous suspension as abrading medium. Indentation of the samples was done with a Vickers diamond micro-indenter with $0.5 \mathrm{~N}(2.5 \mu \mathrm{m}$ thick films $)$ and $1 \mathrm{~N}(5 \mu \mathrm{m}$ thick films) loads during approximately $20 \mathrm{~s}$ keeping the indentation depth around $20 \%$ of the sample thickness. Hardness was obtained by measuring the indentation diagonals on an optical microscope using the DIC (differential interference contrast) technique. In all cases hardness was calculated from the average of a series of 9 different indentations. Residual internal stress was obtained by the substrate bending method, using a Dektak IIA stylus profilometer.

\section{Results and Discussions}

In Table 1 one can see the average measured values of hardness and abrasive wear rates for as deposited SiC films compared to those of WC-Co substrates. It is noteworthy that the $\mathrm{SiC}$ hardness value is twice as high as the one of uncoated hardmetal and is even higher than the one reported for crystalline $\mathrm{SiC}^{1,18}$. Also, the wear rate of $\mathrm{SiC}$-coated $\mathrm{WC}-\mathrm{Co}$ is reduced by a factor of two when compared to uncoated ones.
In order to investigate direct effects of thermal annealing upon mechanical properties of SiC films with a minimal influence of oxidation, samples deposited onto silicon substrates were annealed in vacuum. As shown in Fig. 1 the internal stress is reduced to essentially zero by annealing at high temperatures without any appreciable effect upon the material hardness. Indeed, the curvatures of the SiC-covered $\mathrm{Si}$ substrates could not be distinguished by profilometry from a bare Si wafer after annealing the samples at temperatures equal to or higher than $900{ }^{\circ} \mathrm{C}$. Therefore, these results are presented as zero-stress in Fig. 1. This result is remarkable since in general high hardness for amorphous films is accompanied by high internal stress. One possible explanation for this phenomena is the crystallization of the material, what would produce an unstressed material with the known $\mathrm{SiC}$ high hardness. This issue remains to be further investigated.

Hardmetal samples were annealed at high temperatures in air and inspected in an optical microscope. Loose oxida-

Table 1. Measured properties of coated and uncoated WC-Co substrates.

\begin{tabular}{lccc}
\hline Material & Hardness $(\mathrm{GPa})$ & Wear rate $\left(\mathrm{mm}^{3} / \mathrm{mm} . \mathrm{N}\right)$ & $\mathrm{T}_{\mathrm{MAX}}\left({ }^{\circ} \mathrm{C}\right)$ \\
\hline WC-Co & $15.9 \pm 1.6$ & $2.29 \pm 0.08 \times 10^{-7}$ & $\sim 500^{\circ} \mathrm{C}$ \\
SiC/WC-Co & $30.6 \pm 1.9$ & $1.16 \pm 0.02 \times 10^{-7}$ & $>700{ }^{\circ} \mathrm{C}$ \\
\hline
\end{tabular}

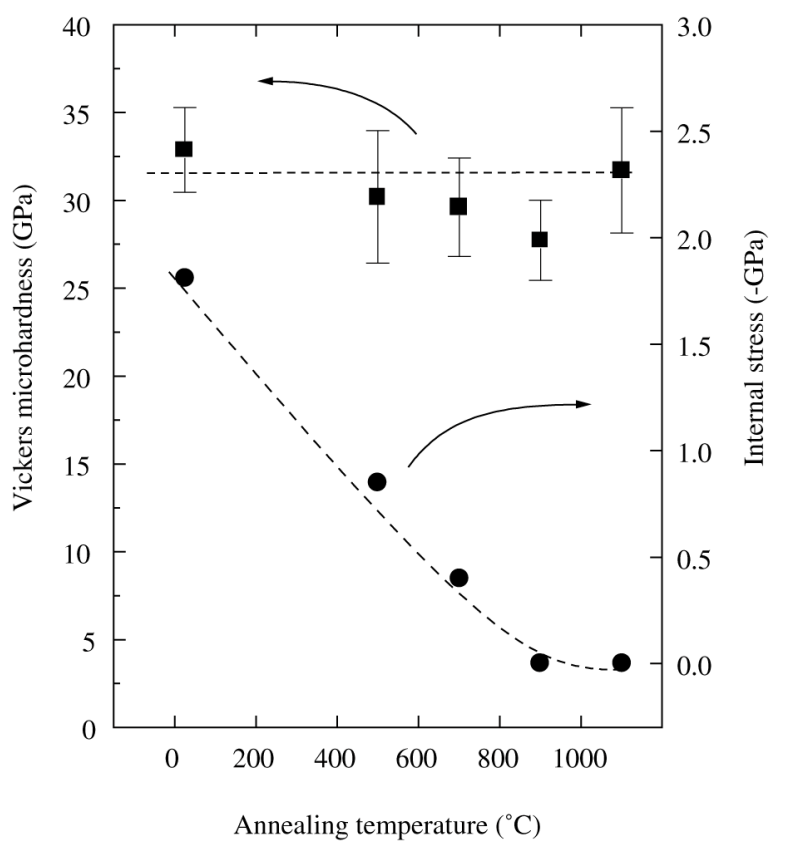

Figure 1. Hardness and compressive residual internal stress as a function of annealing temperature of $\mathrm{SiC}$ films deposited on silicon substrates. 

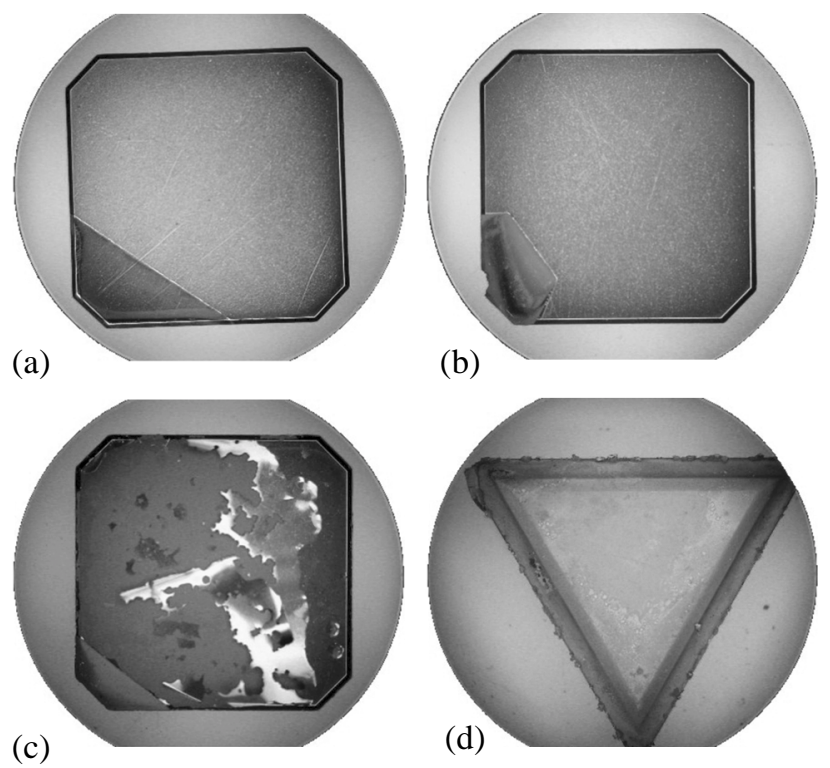

Figure 2. Aspect of hardmetal cutting tools: (a): as deposited; (b) and (c): $\mathrm{SiC}$ coated after $30 \mathrm{~min}$ annealing in ambient air at 700 and $800{ }^{\circ} \mathrm{C}$, respectively; (d): TiN coated after 30 min annealing in ambient air at $800{ }^{\circ} \mathrm{C}$.

tion products (a greenish powder) were observed on uncoated WC-Co surfaces for annealing temperatures of $600{ }^{\circ} \mathrm{C}$ increasing in thickness for higher temperatures. In Fig. 2a and 2b, photographs of as-deposited and annealed $\left(70{ }^{\circ} \mathrm{C}\right)$ samples, respectively, are shown. It is evident from these pictures that no signs of oxidation appear on coated surfaces. However, at $800^{\circ} \mathrm{C}$ the coatings peel off from the substrates (Fig. 2c). It must be noted, however, that this is due to the growth of the oxide under the $\mathrm{SiC}$ films, starting from the edges of the sample, rather than a real destruction of the coatings. Indeed, large self-sustained $\mathrm{SiC}$ films could be found all over the samples. For sake of comparison, annealing of a TiN CVD-coated commercial tool at $800{ }^{\circ} \mathrm{C}$ resulted in strong oxidation and total consumption of the coating (Fig. 2d).

Figure 3 shows hardness values for coated and uncoated samples after thermal annealing. In close agreement with the results obtained for silicon substrates, hardness of coated surfaces was found not to be affected by annealing. On the other hand, the hardness of the uncoated tools is strongly degraded at temperatures higher than about $500{ }^{\circ} \mathrm{C}$, reaching to one sixth of the original values at $700{ }^{\circ} \mathrm{C}$. The observed degradation of mechanical properties of uncoated WC-Co tools is due to severe surface oxidation of this material that results in an oxide layer with reduced hardness.

Abrasive wear rates of annealed coated and uncoated samples are presented in Fig. 4. One can see that measured

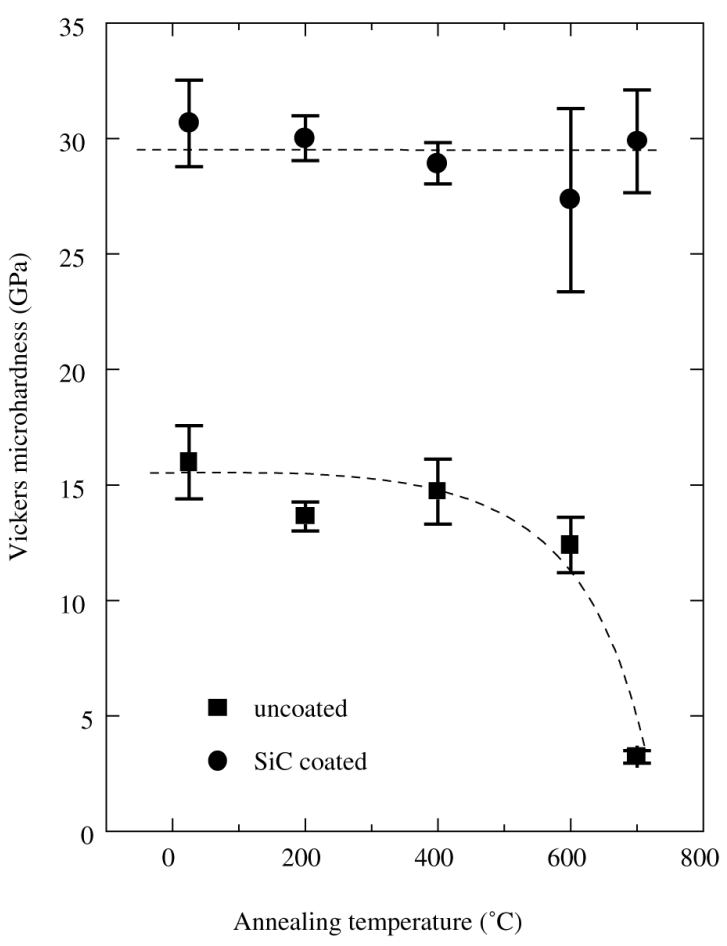

Figure 3. Hardness of uncoated and SiC-coated WC-Co surfaces as a function of annealing temperature (annealing time of $30 \mathrm{~min}$ in air).

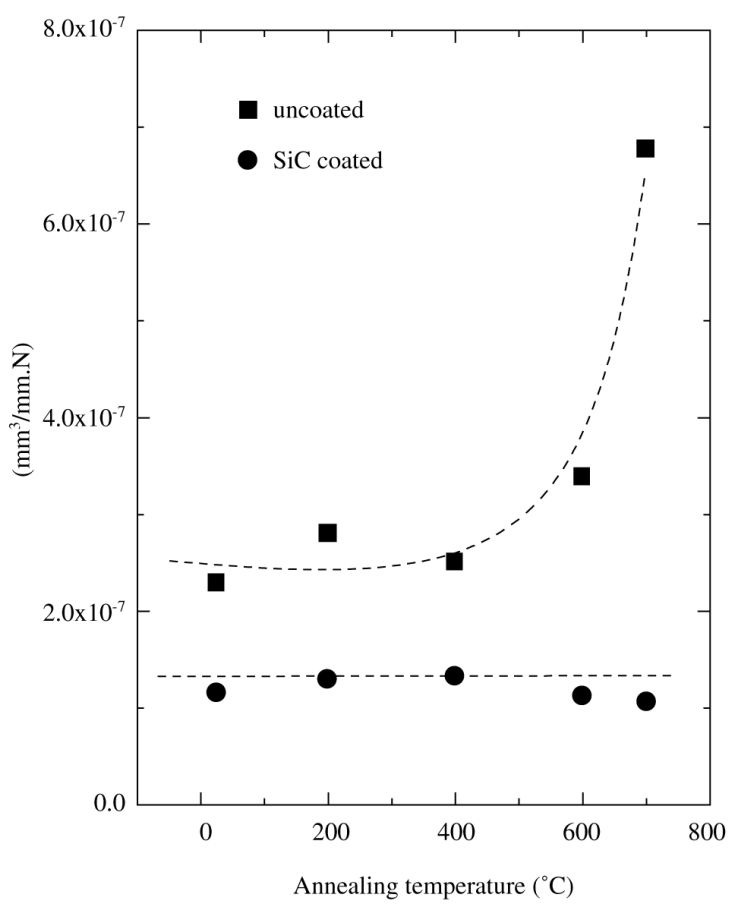

Figure 4. Wear rates of uncoated and SiC-coated WC-Co surfaces as a function of annealing temperature (annealing time of $30 \mathrm{~min}$ in air). 
wear rates of coated surfaces were almost unchanged due to annealing, while that of bare WC-Co started to increase at about $500{ }^{\circ} \mathrm{C}$. Again, this is a deleterious effect of surface oxidation starting at this temperature. Taking these results (hardness and wear resistance) into account we included in Table 1 estimated maximum work temperatures $\left(\mathrm{T}_{\mathrm{MAX}}\right)$ for SiC-coated and uncoated WC-Co tools. One should note, however, that the value for coated substrates was limited by the adhesion failure due to the growth of oxide layer beneath the film as explained before.

\section{Conclusions}

High quality silicon carbide films were successfully deposited on tungsten carbide cutting tools. Coated substrates were found to be twice as hard and wear resistant as uncoated ones. Upon thermal annealing severe oxidation was found to occur on the surface of uncoated WC-Co at temperatures over $500{ }^{\circ} \mathrm{C}$ leading to degradation of its hardness and wear resistance. No signs of oxidation were found to occur in case of coated tools so that mechanical properties remained unchanged up to $700{ }^{\circ} \mathrm{C}$. At higher annealing temperatures, however, the WC-Co oxidation caused the films to peel off from substrates. Annealing of films deposited on silicon substrates showed, however, that the coatings properties may remain unaffected up to $1000{ }^{\circ} \mathrm{C}$.

\section{Acknowledgements}

This work was supported by CAPES and CNPq Brazilian agencies. The authors are also grateful to Sandvik do Brasil which kindly supplied the WC-Co cutting tools.

\section{References}

1. Ohring, M. The materials science of thin films, Academic Press, San Diego, EUA, p. 552, 1992.

2. Ulrich, S.; Theel, T.; Schwan, J.; Batori, V.; Scheib, M.; Ehrhardt, H. Diam. And Rel. Mat., v. 6, p. 645, 1997.

3. Costa, A.K.; Camargo Jr., S.S.; Achete, C.A.; Carius, R.
Thin Sol. Films, v. 377-378, p. 243, 2000.

4. Laidani, N.; Capelletti, R.; Elena, M.; Guzman, L.; Mariotto, G.; Miotello, A.; Ossi, P.M. Thin Sol. Films, v. 223, p. 14, 1993.

5. Ordine, A.; Achete, C.A.; Mattos, O.R.; Margarit, I.C.P.; Camargo Jr., S.S.; Hirsch, T. Surf. Coat. Technol., v. 133-134, p. 583, 2000.

6. Riviere, J.-P.; Delafond, J.; Misaelides, P.; Noli, F. Surf. Coat. Technol., v. 100-101, p. 243, 1998.

7. Chalker, P.R.; Johnston, C.; Romani, S.; Ayres, C.F.; Buckley-Golder, I.M.; Krötz, G.; Angerer, H.; Müller, G.; Veprek, S.; Kunstmann, T.; Legner, W.; Smith, L.; Leesse, A.B.; Jones, A.C.; Rushworth, S.A. Diam. Relat. Mater, v. 4, p. 632, 1995.

8. Haghiri-Gosnet, A.M.; Rousseaux, F.; Kebabi, B.; Ladan, F.R.; Mayeux, C.; Madouri, A.; Decanini, D.; Bourneix, J.; Carcenac, F.; Launois, H.; Wisniewski, B.; Gat, E.; Durand, J. Joun. Vac. Sci. Tech. B, v. 8, p. 1562, 1990.

9. Hirohata, Y.; Kobayashi, M.; Maeda, S. Thin Sol. Films, v. 63 , p. $237,1979$.

10. Sung, H.; Erkens, G.; Funken, J.; Voss, A.; Lemmer, O.; Kreutz, E.W. Surf. Coat. Technol., v. 54-55, p. 541, 1992.

11. Zaytouni, M.; Riviere, J.P.; Denanot, M.F.; Allain, J. Thin Sol. Films, v. 287, p. 1, 1996.

12. Yoshihara, H.; Mori, H.; Kiuchi, M. Thin Sol. Films, v. 76, p. 1, 1981.

13. Wasa, K.; Nagai, T.; Hayakawa, S. Thin Sol. Films, v. 31, p. 235, 1976.

14. Simão, R.A.; Costa, A.K.; Achete, C.A.; Camargo Jr., S.S. Thin Sol. Films, v. 377-378, p. 490, 2000.

15. Mari, D.; Bolognini, S.; Feusier, G.; Viatte, T.; Benoit, W. Int. J. Refract. Met. Hard Mater., v. 17, p. 209, 1999.

16. Acchar, W.; Gomes, U.U.; Kaysser, W.A.; Goring, J. Mater. Charact., v. 43, p. 27, 1999.

17. Holmberg, K.; Matthews, A. Coatings tribology, Elsevier, Amsterdam, Holanda, p. 352-360, 1994.

18. Mc Colm, I.J. Dictionary of Ceramic Science and Engineering, Plenum Publishing Co., $2^{\text {nd }}$ edition, 1994. 